\title{
Erratum to: A phase II experience evaluating quality of life and survival in linac-based SBRT for prostate cancer
}

\author{
Albert DeNittis $^{1,2}$ - Yue Wang ${ }^{3}$ - Abimbola Orisamolu ${ }^{1}$ - Saritha Ravella ${ }^{1}$. \\ David Gasalberti ${ }^{1}$ - David Wang ${ }^{1}$
}

Published online: 27 September 2016

(C) Springer-Verlag Berlin Heidelberg 2016

Erratum to: J Radiat Oncol

DOI: 10.1007/s13566-016-0249-4

The original version of this article unfortunately contains an error. The second author's name "Wang Yue" should be "Yue Wang". The correct author name is now presented in the author group.

The authors apologize for any inconvenience with regard to the error.

The online version of the original article can be found at http/dx.doi.org/ 10.1007/s13566-016-0249-4.

Albert DeNittis

denittisa@mlhs.org

1 Department of Radiation Oncology, Lankenau Medical Center Main Line Health, Wynnewood, PA 19096, USA

2 Lankenau Institute for Medical Research, Wynnewood, PA 19096, USA

3 Department of Medical Oncology, Lankenau Medical Center, Wynnewood, PA 19096, USA 